\title{
HUBUNGAN KUALITAS PELAYANAN ASUHAN KEPERAWATAN DENGAN TINGKAT KEPUASAN PASIEN DI RUANG INTERNA RSUD KOTA KOTAMOBAGU
}

\author{
Darmin \\ Program Studi Kesehatan Masyarakat Institut Kesehatan dan Teknologi Graha Medika, \\ Kotamobagu, Indonesia \\ Email: darmin@stikesgrahamedika.ac.id
}

\begin{abstract}
Abstrak
Peningkatkan kualitas pelayanan kesehatan bertujuan mencapai kepuasan pasien terutama pada pasien rawat inap dengan memperhatikan pelayanan administrasi rumah sakit, pelayanan dokter, sarana medis dan obatobatan, kondisi fasilitas rumah sakit, dan pelayanan keperawatan. Penelitian ini bertujuan untuk menganalisis hubungan kualitas pelayanan asuhan keperawatan dengan tingkat kepuasan pasien di Ruang Interna RSUD Kota Kotamobagu. Penelitian ini menggunakan metode Cross Sectional, dengan sampel 39 keluarga pasien, pengambilan sampel menggunakan rumus purposiv sampling. Analisa yang digunakan ialah univariat dan bivariat dengan menggunakan uji Chi Square. Hasil penelitian menunjukkan bahwa terdapat hubungan kualitas pelayanan asuhan keperawatan dengan tingkat kepuasan pasien di Ruang Interna RSUD Kota Kotamobagu dengan hasil $p$ Value $=0,000$. Berdasarkan hasil penelitan ini disimpulkan terdapat hubungan antara kualitas pelayanan asuhan keperawatan dengan tingkat kepuasan pasien di Ruang Interna RSUD Kota Kotamobagu. Penelitian ini menyarankan agar Perlu ditingkatkan kualitas pelayanan khususnya dalam palayanan asuhan keperawatan sehingga kepuasan pasien rawat inap dapat meningkat dengan sendirinya.
\end{abstract}

Kata kunci: Kualitas pelayanan, Asuhan keperawatan, Kepuasan pasien

\begin{abstract}
Improving the quality of health services aims to achieve patient satisfaction, especially in inpatients by paying attention to hospital administration services, doctor services, medical facilities and medicines, condition of hospital facilities, and nursing services. This study aims to analyze the relationship between the quality of nursing care services and the level of patient satisfaction in the Internal Room of the Kotamobagu City Hospital. This study used a cross sectional method, with a sample of 39 patients' families, sampling using a purposive sampling formula. The analysis used is univariate and bivariate using Chi Square test. The results showed that there was a relationship between the quality of nursing care services and the level of patient satisfaction in the Internal Room of the Kotamobagu City Hospital with p Value $=0.000$. Based on the results of this study, it was concluded that there was a relationship between the quality of nursing care services and the level of patient satisfaction in the Internal Room of the Kotamobagu City Hospital. This study suggests that the quality of service needs to be improved, especially in nursing care services so that inpatient satisfaction can increase by itself.
\end{abstract}

Keywords: Service Quality, Nursing Care, Patient Satisfaction

\section{Pendahuluan}

Kesehatan merupakan kebutuhan dasar manusia untuk dapat hidup layak dan produktif, oleh kerena itu dibutuhkan penyelenggaraan pelayanan kesehatan yang terkendali biaya dan kualitasnya. Jaminan pelayanan kesehatan yang bermutu dan terjangkau telah diatur dalam undang- undang 
MIRACLE JOURNAL

https://ojs.unhaj.ac.id/index.php/mj
MIRACLE JOURNAL

e-ISSN $2774-4663$

Vol 1, No 2, Juli 2021

Hal 29 - 35

Nomor 36 Tahun 2009 tentang kesehatan yang menegaskan bahwa setiap orang mempunyai hak yang sama dalam memperoleh akses atau sumber daya di bidang kesehatan dan memperoleh pelayanan kesehatan yang aman, bermutu, dan terjangkau. Hak dalam memperoleh pelayanan kesehatan juga diatur dalam pasal $28 \mathrm{H}$ ayat (1) dinyatakan bahwa "setiap orang hendak hidup sejahtera lahir dan batin, bertempat tinggal, dan mendapatkan lingkungan hidup yang baik dan sehat serta berhak memperoleh pelayanan kesehatan" dan pasal 34 ayat (3) "Penyediaan fasilitas pelayanan kesehatan dan fasilitaspelayanan umum yang baik adalah tanggungjawab Negara”(Suaib, 2015).

Tenaga Keperawatan merupakan ujung tombak dari pelayanan yang ada di fasilitas kesehatan termasuk rumah sakit, sebagai pelaksana asuhan keperawatan, Selama 24 jam tenaga keperawatan memberikan pelayanan kepada pasien, oleh sebab itu perawat memegang peranan yang cukup dominan dalam rangka memberikan kepuasan kepada pelanggan atau pasien. Kualitas pelayanan keperawatan bersifat komperehensif, mencakup pelayanan bio-psiko-sosio-kultural dan spiritual. Dalam kepuasan hal terpenting adalah persepsi pelanggan, bukan hal-hal yang aktual seperti yang dipikirkan produsen atau pemberi jasa. Masyarakat sebagai pengguna jasa mempresepsikan baik buruknya pelayanan di instalasi rawat inap tergantung bagaimana perawat memberikan asuhan keperawatan (Gultom, 2013).

Pelayanan keperawatan yang dilakukan di rumah sakit merupakan sistem pengelolaan asuhan keperawatan yang diberikan kepada pasien agar menjadi berdaya guna dan berhasil guna. Pengetahuan tentang manajemen keperawatan, kemampuan memimpin orang lain, dan keterampilan klinis merupakan yang harus dikuasai oleh tenaga keperawatan agar Sistem pengelolaan asuhan keperawatan akan berhasil.

Asuhan keperawatan terdiri dari kegiatan mulai dari pengkajian, perencanaan, implementasi rencana, dan evaluasi tindakan keperawatan, Asuhan keperawatan yang bermutu dapat dicapai jika pelaksanaan asuhan keperawatan dipersepsikan sebagai suatu kehormatan yang dimiliki oleh perawat dalam memperlihatkan haknya untuk memberikan asuhan yang manusiawi, aman, serta sesuai dengan standar dan etika profesi keperawatan (Isti, 2009).

Kepuasan pelanggan akan terpenuhi jika melampaui harapannya, Kepuasan adalah perasaan senang seseorang yang berasal dari perbandingan antara harapan dan kinerja. Apabila kinerja lebih tinggi daripada yang diharapkan maka kepuasan pelanggan akan meningkat. Loyalitas pelanggan dan profitabilitas perusahaan yang maksimal dalam jangka panjang diperoleh melalui kepuasan pelanggan. Dalam upayanya meningkatkan pelayanan dan meningkatkan kepuasan pasien Rumah sakit perlu mengadakan survey kepuasan pasien untuk dapat mengetahui harapan pasien dan kinerja penyelenggara layanan kesehatan, mengingat bahwa harapan merupakan ukuran pembanding untuk menilai kualitas pelayanan di fasilitas kesehatan (Nursalam, 2011).

Kemampuan dalam memahami kebutuhan dan keinginan pasien adalah hal penting karena pasien yang puas merupakan aset yang sangat berharga, apabila pasien merasa puas mereka akan kembali berobat ke fasilitas kesehatan tersebut, sebaliknya jika pasien merasa tidak puas mereka akan memberitahukan dua kali lebih hebat kepada orang lain tentang pengalaman buruknya dan akan pindah ke fasilitas kesehatan lainnya (Kaseger et al., 2021).

Pengukuran kepuasan pasien secara berkala perlu dilakukan oleh seluruh fasilitas kesehatan termasuk rumah sakit. Hal ini disebabkan karena masyarakat semakin kritis dan semakin menuntut pelayanan yang berkualitas dari rumah sakit. Hasil pengukuran kepuasan pasien dapat dijadikan 
sebagai referensi bagi fasilitas kesehatan atau rumah sakit untuk meningkatkan kualitas pelayanan pada periode selanjutnya (Efendi, 2015). Semakin ketatnya persaingan antara penyedia jasa pelayanan kesehatan serta pasien yang semakin selektif dan berpengetahuan, mengharuskan semua fasilitas pelayanan kesehatan termasuk rumah sakit untuk selalu meningkatkan kualitas pelayanan secara terus menerus. Peningkatkan kualitas pelayanan kesehatan bertujuan mencapai kepuasan pasien terutama pada pasien rawat inap dengan memperhatikan pelayanan administrasi rumah sakit, pelayanan dokter, sarana medis dan obat-obatan, kondisi fasilitas rumah sakit, dan pelayanan keperawatan

Rahmawati (2014) dalam hasil penelitiannya Rawat Inap RSUD Bangkalan Surabaya mengatakan bahwa kualitas pelayanan rumah sakit akan memberikan pengaruh yang besar bagi kepuasan pasien, sehingga untuk memberikan kepuasan bagi pasiennya setiap rumah sakit harus memberikan pelayanan yang berkualitas dan memuaskan.

Bata et al. (2013) hasil penelitian menunjukkan bahwa kualitas responsiveness yang dirasakan responden, yaitu perawat tidak mampu mendengarkan keluhan dari pasien, tidak memberikan informasi yang jelas sebagai hak dari pasien untuk mengetahui keadaan penyakit yang di derita oleh pasien. Kecepatan petugas dalam melayani pasien juga dikeluhkan oleh sebagian responden, pasien dan keluarga pasien mengharapkanpelayanan yang lebih cepat sesuai keluhan yang mereka alami.

Hasil studi pendahuluan yang dilakukan peneliti pada Februari 2019 terdapat 156 pasien di Ruangan interna, dari hasil observasi dan wawancara yangpeneliti lakukan pada 10 pasien, 6 pasien menyampaikan cukup puas terhadap pelayanan yang diberikan perawat namun ada 4 pasien yang merasa tidak puas dengan pelayanan yang diberikan perawat karena perawat kurang tanggap dengan keluhan pasien, perawat tidak selalu memberikan informasi kepada pasien sebelum melakukan tindakan, kurangnya komunikasi antara perawat dan pasien,pasien tidak puas dengan fasilitas pelayanan yang kurangmemadai.

Berdasarkan fenomena dan data tersebut maka peneliti tertarik melakukan penelitian untuk menganalisis hubungan kualitas pelayanan asuhan keperawatan dengankepuasan pasien di Ruang Nifas RSUD Kota Kotamobagu.

\section{Metode Penelitian}

Rancangan penelitian yaitu deskriptif analitik dengan menggunakan metode cross sectional. Penelitian inidilaksanakan pada bulan Februari 2019 sampai Juli 2019. Penelitian ini dilaksanakan di Wilayah Ruang Interna RSUD Kota Kotamobagu. Populasi dalam penelitian ini adalah semua pasien di Ruang Interna RSUD Kota Kotamobagu dengan total 156 orang.

Jumlah populasi sudah diketahui jumlahnya, maka pengambilan jumlah sampel menggunakan purposive sampling yaitu teknik penetapan sampel dengan cara memilih sampel di antara populasi sesuai dengan yang dikehendaki sampel dalam penelitian ini yaitu 39 orang. data dianalisis dalam bentuk univariat dan bivariat. Analisisunivariat untuk mendapatkan gambaran distribusi frekuensi dari variabel-variabel penelitian yaitu kualitas pelayanan asuhan keperawatan, tingkat kepuasan pasien, dalam bentuk datakategori. Analisis dilakukan dengan statistik deskriptif berupa distribusi frekuensi. Analisis bivariat bertujuan untuk mengetahui ada atau tidaknya hubungan yang bermakna antara variabel bebas yaitu, kualitas pelayanan asuhan keperawatan dengan variabel terikat yaitu stres yang 
dialami tingkat kepuasan pasien di Ruang Interna RSUD Kota Kotamobagu dalam data kategori. Analisis dilakukan dengan uji Chi-Square.

\section{Hasil dan Pembahasan}

\section{Karekteristik Responden}

Karakteristik responden dalam penelitian merupakan data pribadi yang dimiliki responden yang dalam hal ini terdiri dari umur, jenis kelamin dan pendidikan.

Karakteristik Responden Berdasarkan Umur

Tabel 1 Distribusi Frekuensi menurut Umur Pasien di Ruang Interna RSUD Kota Kotamobagu

\begin{tabular}{ccc}
\hline Umur & Frekuensi & Persentase $(\%)$ \\
\hline $17-25$ Tahun & 10 & 25,6 \\
$26-35$ Tahun & 12 & 30,8 \\
$36-45$ Tahun & 14 & 35,9 \\
$46-55$ Tahun & 3 & 7,7 \\
\hline Total & 39 & 100,0 \\
\hline
\end{tabular}

Berdasarkan Tabel 1 di atas menunjukan bahwa sebagian besar responden berumur 36 - 45 Tahun berjumlah 14 orang $(43,9 \%)$.

\section{Karakteristik Responden Berdasarkan Jenis Kelamin}

Tabel 2 Distribusi Frekuensi menurut Jenis Kelamin Pasien di Ruang Interna RSUD Kota Kotamobagu

\begin{tabular}{ccc}
\hline Jenis Kelamin & Frekuensi & Persentase (\%) \\
\hline Laki-laki & 18 & 46,2 \\
Perempuan & 21 & 53,8 \\
\hline Total & 39 & 100,0 \\
\hline
\end{tabular}

Berdasarkan Tabel 2 di atas menunjukan bahwa sebagian besar resonden berjenis kelamin perempuan 21 orang $(53,8 \%)$.

\section{Karakteristik Responden Berdasarkan Pendidikan}

Tabel 3 Distribusi Frekuensi menurut Pendidikan Pasien di Ruang Interna RSUD Kota Kotamobagu

\begin{tabular}{ccc}
\hline Pendidikan & Frekuensi & Persentase (\%) \\
\hline SD & 6 & 15,4 \\
SMP & 8 & 20,5 \\
SMA & 19 & 48,7 \\
Perguruan Tinggi & 6 & 15,4 \\
\hline Total & 39 & 100,0 \\
\hline
\end{tabular}

Berdasarkan Tabel 3 di atas menunjukan bahwa sebagian besar responden berpendidikan SMA yang berjumlah 19 orang $(48,7 \%)$.

\section{Kualitas Pelayanan Asuhan Keperawatan}

Tabel 4 Distribusi Frekuensi Menurut Kualitas Pelayanan Asuhan Keperawatan di Ruang Interna RSUD Kota Kotamobagu

\begin{tabular}{ccc}
\hline $\begin{array}{c}\text { Kualitas Pelayanan Asuhan } \\
\text { Keperawatan }\end{array}$ & Frekuensi & Persentase (\%) \\
\hline Efektif & 30 & 76,9 \\
Tidak Efektif & 9 & 23,1 \\
\hline Total & 39 & 100,0 \\
\hline
\end{tabular}


Berdasarkan tabel 4 di atas menunjukan bahwa dari sebagian besar responden merasakan bahwa kualitas pelayanan asuhan keperawatan yang diberikan efektif yaitu 30 orang $(76,9 \%)$.

Kepuasan Pasien

Tabel 5 Distribusi Frekuensi menurut Kepuasan Pasien di Ruang Interna RSUD Kota Kotamobagu

\begin{tabular}{ccc}
\hline Kepuasan Pasien & Frekuensi & Persentase $(\%)$ \\
\hline Puas & 30 & 76,9 \\
Tidak Puas & 9 & 23,1 \\
\hline Total & 39 & 100,0
\end{tabular}

Berdasarkan tabel 5 di atas diketahui bahwa sebagian besar responden menyatakan puas dengan kualitas pelayanan asuhan keperaeatan yang diberikan yaitu 30 orang (76,9\%).

\section{Analisa Bivariat}

Hubungan Kualitas Pelayanan Asuhan Keperawatan dengan Kepuasan Pasien Di Ruang Interna RSUD Kota Kotamobagu

Tabel 6 Hubungan Kualitas Pelayanan Asuhan Keperawatan dengan Kepuasan Pasien Di Ruang Interna RSUD Kota Kotamobagu

\begin{tabular}{lrrrrrrr}
\hline \multirow{2}{*}{$\begin{array}{l}\text { Kualitas Pelayanan } \\
\text { Asuhan Keperawaatan }\end{array}$} & \multicolumn{4}{c}{ Kepuasan Pasien } & \multirow{2}{*}{ Jumlah } & \multirow{2}{*}{ p value } \\
\cline { 2 - 6 } & \multicolumn{1}{c}{ P } & \multicolumn{1}{c}{$\%$} & $\mathrm{n}$ & \multicolumn{1}{c}{$\%$} & \multicolumn{1}{c}{$\mathrm{N}$} & \multicolumn{1}{c}{$\%$} & \\
\hline Efektif & 30 & 76,9 & 0 & 0,0 & 30 & 76,9 & \multirow{2}{*}{0.000} \\
Tidak Efektif & 0 & 0,0 & 9 & 23,1 & 9 & 23,1 & \\
\hline Jumlah & 30 & 76,9 & 9 & 23,1 & 39 & 100,0 & \\
\hline
\end{tabular}

Berdasarkan Tabel 6 di atas didapat hasil penelitian menunjukan kualitas pelayanan asuhan keperawatan efektif dengan kepuasan pasien puas yaitu sebanyak 30 responden (76,9\%), sedangkan kualitas pelayanan asuhan keperawatan tidak efektif dengan kepuasan pasien tidak puas yaitu sebanyak 9 responden $(23,1 \%)$. Hasil uji statistic Chi Square diperoleh nilai $p=0,000$ atau $<P=0,05$. Hal ini berarti terdapat hubungan kualitas pelayanan Asuhan Keperawatan dengan kepuasan pasien di Ruang Interna RSUD Kota Kotamobagu.

Hubungan Kualitas Pelayanan Asuhan Keperawatan Dengan Kepuasan Pasien Di Ruang Interna RSUD Kota Kotamobagu. Hasil penelitian menunjukan kualitas pelayanan asuhan keperawtan efektifdengan kepuasan pasien puas yaitu sebanyak 30 responden (76,9\%), sedangkan kualitas pelayanan administrasi BPJS tidak efektif dengan kepuasan pasien tidak puas yaitu sebanyak 9 responden $(23,1 \%)$. Hasil ujistatistic Chi Square diperoleh nilai $\mathrm{P}=0,000$ atau $<\mathrm{P}=0,05$. Hal ini berarti terdapat hubungan kualitas pelayanan Asuhan Keperawatan dengan kepuasan pasien di Ruang Interna RSUD Kota Kotamobagu.

Hasil penelitian ini sejalan dengan penelitian Mubin dan Jalal (2014) yang menyatakan adanya hubungan antarakualitas pelayanan keperawatan dengan kepuasan pasien. Dimana kepuasanpasien sangat bergantung pada persepsi pasien terhadap mutu pelayanan keperawatan itu sendiri. Pada penelitian Krisnawati et al (2017) juga didapatkan adanya hubungan antara mutu perawat dengan kepuasan pasien, dimana mutu perawat dalam melakukan asuhan keperawatan adalah baik dengan persentase $(68,42 \%)$, dan kepuasanpasien didapatkan sangat puas dengan persentase $(63,16 \%)$. Mutu yang baik pada pelayanan keperawatan di rumah sakit akan meningkatkan level kepuasan pasien. Pengukuran kepuasan pasien sangat penting untuk menyediakan pelayanan kesehatan khususnya padamutu keperawatan yang lebih baik, nyaman, cepat, ramah, dan perhatian (Patima, 2013).

Hasil observasi yang dilakukan peneliti, terdapat beberapa faktor yang mempengaruhi kepuasan pasien terhadap kualitas pelayanan keperawatan diantaranya (caring, kolaborasi, kecepatan, empati, courtesy, sicerity, komunikasi teraupetik, ketanggapan, kehandalan, jaminan dan bukti langsung (Nursalam, 2011; Triwibowo, 2013; Nursalam, 2013). Dimana sikap sicerity (jujur) dan sikap cepat tanggap perawat dapat terlihat lebih 
maksimal di RSUD Kota Kotamobagu. Hasil tersebut didapatkan dari penilaian pasien terhadap kualitas pelayanan asuhan keperawatan sehingga pasien menilai baik buruknya pelayanan rumah sakit ada pada pelayanan keperawatan karena perawat merupakan pelaksana asuhan keperawatan yang 24 jam berada dengan pasien.

Pada pemenuhan asuhankeperawatan yang baik hingga memberikan dampak kepuasan terhadap pasien, diperlukan motivasi perawat dalam menerapkan asuhan perawat secara individu sesuai dengan keadilan dengan penghargaan yang perawat terima seimbang terhadap sesuatu yang perawat kerjakan. Semakin tinggi motivasi perawat dalam pemenuhan asuhan keperawatan yang berkualitas maka, akan berdampak terhadap kepuasan pasien di rumah sakit (Yanti dan Bambang, 2013). Hal ini tidaksejalan dengan penelitian oleh Mulyono et al (2013) memperlihatkan dariperawat yang motivasi kerjanya baik, sebagian besar $(55,56 \%)$ kinerjanya tidak baik, begitu juga pada perawat yang motivasi kerjanya tidak baik sebagian besar $(64,29 \%)$ kinerjanya dalam pemenuhan asuhan tidak baik. Sedangkan penelelitian yang dilakukan oleh Budiawan (2015) diketahui bahwa motivasi perawat yang baik akan mempengaruhi kinerja perawat yang baik juga dalam pelaksanaan asuhan keperawatan.

Asumsi peneliti adanya hubunganantara kualitas pelayanan asuhan keperawatan dengan kepuasan pasien di Ruang Interna RSUD Kota Kotamobagudengan beberapa dimensi diatas. Kualitas pelayanan Asuhan Keperawatan yang baik dan berkualitas akan mempengaruhi tingkat kepuasan pasien yang tinggi. Dengan demikian dari didapatkan hasil yang baik RSUD Kota Kotamobagu senantiasa menjaga komitmen kualitas yang baik sampai kapanpun sehingga akan memberikan dampak positif terhadap tenaga kerja perawat dan rumah sakit itu sendiri.

\section{Kesimpulan}

Kualitas pelayanan asuhan keperawatan di Ruang Interna RSUD Kota Kotamobagu sebagian besar responden merasa pelayanan asuhan keperawatan efektif. Kepuasan pasien di Ruang Interna RSUD Kota Kotamobagusebagian pasien merasa puas. Ada hubungan hubungan kualitas pelayanan asuhan keperawatan dengan kepuasan pasien di Ruang Interna RSUD Kota Kotamobagu. Perlu dilakukan usaha dalam meningkatkan kualitas pelayanan keperawatan di RSUD Kota Kotamobagu terhadap pasien terutama pelayanan rawat inap karena semakin tinggi kualitas pelayanan dalam pemberian asuhan keperawatan yang diberikan maka akan memberikan kepuasan kepada pasien.

\section{Referensi}

Arikunto, S. (2010). Prosedur Penelitian Suatu Pendekatan Praktik. Jakarta: Rineka Cipta.

Bahtiar. (2013). Hubungan Kualitas Pelayanan Keperawatan Dengan Kepuasan Pasien Rawat Inap Di Rsud Pangkajene Dan Kepulauan .Skripsi. Makassar : UINAlauddin.

Bata, Y, W, Alwy, Darmawansyah (2013). Hubungan Kualitas Pelayanan Kesehatan dengan Kepuasan Pasien Pengguna Askes Sosial pada Pelayanan Rawat Inap di RSUD Lakipadada Kabupaten Tana Toraja [Skripsi].Makassar: Universitas Hasanuddin.

Budianto, Agus dan Gwendolyn Ingrid Utama. (2010). Aspek Jasa Pelayanan Kesehatan dalam Perspektif PerlindunganKonsumen. Bandung: Karya PutraDarwati. 
Efendi, F. (2015). Keperawatan Kesehatan Komunitas Teori dan Praktek Dalam Keperawatan. Jakarta: Salemba Medika.

Gultom, J. R. (2013). AnalisisKepuasan Pasien terhadap Pelayanan Rawat Jalan di Poliklinik Rumah Sakit Azra Tahun 2008. [Skripsi Ilmiah]. Depok: Fakultas Kesehatan Masyarakat Universitas Indonesia.

Isti. (2009). Dokumentasi Keperawatan "DAR”: Panduan, Konsep, Dan Aplikasi. Cetakan kedua. Jogjakarta. Mitra Cendikia.

Kaseger, H., Akbar, H., Amir, H., Astuti, W., \& Rahayu Ningsih, S. (2021). Analisis Faktor Kualitas Pelayanan yang Mempengaruhi Kepuasan Pasien dalam Pelayanan Rawat Jalan di Wilayah Kerja Puskesmas X. Jurnal.Uimedan.Ac.Id, 3(1), 23-33. https://jurnal.uimedan.ac.id/index.php/JURNALFARMASI/article/view/538

Kotler, Phillip. (2009). Manajemen Pemasaran, Edisi 13. Jakarta: Erlangga.

Kurniati. (2013). Kepuasan Pasien Rawat Inap Terhadap Pelayanan Perawat di RSU Tugurejo Semarang. Tesis.Semarang: UNDIP.

Notoatmodjo, S. (2007). Promosi Kesehatan dan Ilmu Perilaku. Jakarta: Rineka Cipta.

Nursalam. (2008). Proses Dan Dokumentasi Keperawatan. Jakarta : Salemba Medika.

Nursalam. (2012). Menajemen Keperawatan : Aplikasi Dalam Praktik Keperawatan Profesional Edisi 3. Jakarta: Salemba Medika.

Nursalam. (2011). Proses Dan Dokumentasi Salemba Medika.

Keperawatan, Konsep Dan Praktek. Jakarta :

Tjiptono Fandy dan Diana Anastasia. (2012). Total Quality Manajement, Edisi Revisi. Yogyakarta : Andi. 